\title{
Analysis on Implementation Path of Cultivating Humanistic Spirit in the Teaching of Law
}

Xia Du ${ }^{1, a^{*}}$

${ }^{1}$ Department of law, Qilu University of Technology, Jinan, Shandong, China

a jinanhao2012@126.com

${ }^{*}$ Corresponding author

\begin{abstract}
Humanistic spirit is the soul of the law science, cultivating people with humanities is one of the important tasks of law teaching. Teachers should possess the consciousness of humanistic spirit in the course of law teaching. Teachers should organically combined the humanistic spirit with professional knowledge when preparing lessons, permeate humanistic spirit of law by innovating teaching methods in class, and sublimate the humanistic spirit of law in the course of practice teaching.
\end{abstract}

Keywords: Humanistic Spirit, Teaching of Law, Teaching method.

\section{法学教学中人文精神教育实现路径探析 \\ 杜 霞 $1, \mathrm{a}^{*}$ \\ ${ }^{1}$ 齐鲁工业大学文法学院, 济南, 山东, 中国 \\ a jinanhao2012@126.com \\ “通讯作者}

中文摘要. 人文精神是法学的灵魂, 培养具 有人文素养的法律人是法学教学的重要任 务之一。法学专业教师在向学生传授专业知 识的同时, 更应该在备课、课堂教学和课后 实践等各教学环节树立法学人文精神教育 意识, 通过备课时拓展备课内容挖掘法学人 文精神、课堂上创新教学方法渗透法学人文 精神和实践教学中增强人文精神引领性升 华法学人文精神, 全过程构建法学教学人文 精神教育。

关键词: 人文精神; 法学教学; 教学方法

\section{1. 引言}

马克思・韦伯说过：任何一项事业的背 后都存在着某种决定该项事业发展方向和 命运的精神力。法学从诞生之日起就被赋予 了丰富的人文精神, 成为富含人文精神的一 门社会科学。正义、公平、权利、自由等人 文精神是法学的灵魂, 是法学内在、深层的 精髓与内核, 它深藏于法学背后并决定着法 学的发展方向和命运走向。作为一名法学学 生, 只有深入领悟汲取蕴含在法学深处的人 文精神，才能摆脱流于法律工具主义的现 状, 触及法的内在生命, 真正把持法的本质 与精髓, 才能在将来的职业生涯中秉持正 
义, 以强烈的社会责任感和历史使命感忠实 实现法的价值和作用。作为以培养法律人才 为主要目标的法学教学, 不仅仅承载着专业 知识的传授, 更应将发掘、传播法学人文精 神作为教学的重要使命和内容。那种忽视人 文精神教育的法学教学, 培养出的只能是法 律的行尸走肉, 甚至是践踏法律的次品。因 此, 法学专业教师应在备课、课堂教学、课 外实践等各个教学环节树立法学人文精神 教育意识, 通过在备课时拓展备课内容挖掘 法学人文精神、课堂上创新教学方法渗透法 学人文精神和实践教学中增强人文精神引 领性升华法学人文精神, 在法学教学全过程 贯穿法学教学人文精神教育, 培养兼具法学 专业知识和人文素养的高素质法律工作者。

\section{2. 挖掘人文精神一拓展备课内容}

法学中蕴含着丰富的人文精神, 但人文 精神属于深层次的思想观念, 而非具体的知 识, 它隐含于法律规定、法理知识之中, 学 生只有在教师的挖掘、引导下, 才能透过法 律条文, 体会到法学深层的精神旨意。因此, 教师应摒弃以专业知识为单一备课内容的 做法, 在备课环节增强人文精神教育意识, 努力挖掘法学背后蕴含的动态的人文精神 内涵, 唤醒法学中灵动的人文精神内涵, 将 闪伢着人文精神的法学知识呈现给学生。

例如在准备讲授行政法的历史发展和 中外比较内容时, 可设计通过启发学生思考 我国行政法的发展趋势及评析各国行政法 价值特征, 融入利益一致、服务与合作、信 任与沟通的当代行政法人文精神, 进而引导 学生以这种人文精神去审视我国现行行政 法有关规定。在对《刑法修正案 (八)》备 课中, 深入挖掘其中蕴含的人文精神内涵。 如完善对老年人犯罪和未成年人犯罪从宽 处罚的规定充分体现了人道主义精神, 社区 矫正的首次规定体现了我国刑法教育、挽救 人性的精神体现。在此基础上, 设计指导学 生以当代刑法人文精神审视刑法修正案 （八）的缺憾所在。2012年修订的《刑事诉 讼法》是一部彰显现代人文精神的现代化法 典, 教师应在备课时把握其中蕴含的 “人本 主义” 人文精神, 在专业知识中融入我国刑 事司法中尊重个人的自由、权利和人格尊
严, 承认并尊重其主体地位和诉讼权利, 反 对将其物化、客体化的人文精神。2011年实 施的《侵权责任法》更是处处闪秌着人文精 神的光芒, 应在备课过程中深挖掘其人文教 育资源, 通过 “为什么我国侵权责任法对 于动物伤人、教育机构规定了多种归责原 则?”等问题的设计引导学生感受到我国侵 权责任法是一部即维护自由又保障权利的 衡平法, 它蕴含着公平、自由、权利、和谐 等价值精神, 并依此精神去解析《侵权责任 法》相关规定。

只有教师自己具备了深厚的法学人文 精神, 并让这种精神成为支配其教学行为的 潜意识, 才能自觉地在各专业知识点的讲授 中渗透人文精神的教育。因此教师在备课过 程中应不断挖掘法学专业知识中蕴含的人 文精神, 提高自身的人文素养。只有这样, 才能在教学中以自然的情感交流实现专业 知识与人文精神的 “你中有我、我中有你” 的有机融合, 避免科学知识、人文精神两张 皮教学的错误做法。

\section{3. 渗透人文精神一创新课堂教学方法}

人文精神的虚隐性决定了人文精神教 育不是简单的知识传授, 而是生命的对话、 心灵的流露、感情的交流。因此, 人文精神 的教育需要采取与科学教育不同的方法, 才 能收到良好的效果。教师应当积极创新教学 方法, 以探讨式、模拟实验等多元双向式教 学方式实现促进学生法学人文精神的有效 内化。

首先, 研讨式教学方法有助于引导学生 感悟法学人文精神

研讨式教学方法不同于讲授式教学方 法灌输一接受的单向式教学模式, 它倡导以 学生为学习主体, 在教师指导下, 将课前资 料的查阅、课堂学习交给学生完成, 通过师 生、生生双向互动交流实现知识的内化。研 讨式教学方法所具有的学生主动思考、主动 学习和双向互动的特点很好地契合了人文 精神的自我体验性特征, 促使学生在自我体 验中感悟法学人文精神, 内化人文精神主 旨。

例如在讲授《侵权责任法》时, 将《侵 权责任法》与《民法通则》中相关规定的比 
较分析留给学生, 引导学生围绕 “有哪些不 同点” “为什么会有这样的差异” “这种差 异说明了什么” 等富含人文精神答案的问题 进行课前查资料、课上讨论, 通过查资料学 生完成对特定人文精神的自我学习、自我思 考和自我领悟, 进行自我消化; 通过课堂讨 论, 学生理解的不同的人文精神相互碰撞和 交融, 在师生互动、生生互动中实现人文精 神的自然渗透。

其次, 案例辩论的教学方法可使学生深 刻体验法学人文精神

案例教学是法学教学的常用方法, 但许 多教师在运用这一方法时, 仅是机械地将法 条规定与案例划等号, 这种机械定论式的案 例教学法无法解决学生产生的一些疑惑, 也 起不到深层剖析法学知识作用, 也无法从根 本上提高学生解决实际问题的能力。以人文 精神为指引进行案例解析, 引导学生在一定 法学人文精神指导下, 对对立或冲突的价值 目标进行评判、选定, 可帮助学生提高思考 问题的深度和广度, 从而提高学生在法学人 文精神指导下分析问题、解决问题的能力, 同时在案例辨析中体验法学人文精神的丰 富内涵。

例如在讲授《刑法学》中关于盗窃罪知 识点时, 通过选取具有典型性和具有复杂冲 突性的许霆案, 将对许霆行为定性的众多观 点陈列给学生, 引导学生在 “打击犯罪与保 障人权、防卫社会与刑罚谦抑等权衡” 的人 文精神指导下, 对于许霆行为的罪与非罪、 此罪与彼罪作出合法合理的选择和判断。再 如在讲授刑法学公共安全类罪一章时, 选取 国内首个以 “投放危险物质罪” 对环境污染 事件责任人进行刑事处罚的案例即江苏省 盐城 “ 2.20 ” 特大水污染典型案件, 引导学 生围绕 “重大环境污染事故罪” 与 “投放危 险物质罪, 展开辩论, 在定罪理由辨析中体 验其中蕴含的保障人身、财产安全的人文精 神。

再次, 情境式教学方法有助于学生内化 法学人文精神

德国教育家第斯多惠指出: “教学的艺 术不在于传授本领而在于激励、唤醒、鼓 舞”。在教学中创设生动的教学情境, 能充 分调动学生情感, 实现知识的内化。情境式
教学方法能很好地契合人文精神的情感性 特征, 促使学生以积极的态度情感认同、内 化人文精神主旨。

例如犯罪心理学中犯罪心理成因一章, 通过组织学生角色扮演设置一名大学生因 失恋而杀害自己前女友的情境, 犯罪人真挚 的心理告白为学生营造一个走进犯罪人、了 解犯罪成因的教学情境, 在与犯罪人情感的 碰撞中, 学生通过回答如何矫正犯罪人, 体 验到挽救人性的法学人文精神, 同时感悟到 如何培养自己健全的人格品质。

此外, 还可通过教学实验等学生参与式 教学方法实现学生对法学人文精神的内化。 如在犯罪心理学课程教学中, 通过项目教学 法教学方式将部分犯罪类别的心理分析分 解为若干项目, 由学生制定项目目标, 搜集 案件, 完成项目策划, 最后实现项目目标。 如以曾轰动一时的杀人恶魔杨新海案为例, 学生在自我完成项目过程中, 运用犯罪心理 学相关知识追溯其犯罪的根源, 最后在得出 个体内外因素是导致犯罪的原因后, 深刻领 悟到 “犯罪人即是加害人也是受害人” 的寓 意, 从而更加全面认识何谓犯罪、犯罪人, 加深对人性、人的价值理解。

以上教学方法的创新不应仅是教学方 法名称上的变化, 而应是一种实质的创新, 应紧密结合学科特征, 契合人文精神教育 点, 在学生主动参与、师生互动、生生互动 中潜移默化地内化人文精神。同时要处理好 两种关系: 一是教师指导与学生参与的关 系, 学生的参与不是一种 “放羊” 式教学, 而应是在教师有意识的人文精神引导下的 参与。二是互动关系, 特别是师生互动应是 建立在师生平等基础之上的互动。

\section{4. 升华人文精神一增强课后实践的人文性}

作为一种主观性和个体性的人文精神 所期待的并不只是学生简单的掌握和理解, 而是期望能够内化在学生的心理结构中并 得以升华, 进而自觉影响思维及行为, 将认 识转变为自觉行动。课后实践以其学生的实 际体验及自身行动成为塑造学生法学人文 精神, 促进学生内在的法学人文精神转化为 自觉行动的重要途径, 只有通过社会实践, 人文精神才能克服抽象、空洞, 才能使学生 
真正理解人文精神的内在涵义, 产生丰富的 人文情感, 进而实现从人文知识到人文精神 的提升; 才能使学生真正成为充满正义感、 社会责任感的法律工作者, 进而形成为一种 职业习惯。因此, 教师应充分利用好课后实 践这一独特的教学场域, 运用法学实践素 材, 增强实践教学的法学人文精神元素, 将 人文精神贯穿于实践教学全过程, 引导学生 通过实践深化法学人文精神的认知, 通过实 践实现人文精神内化向外化的转变。

例如在学习《环境保护法》过程中, 设 计社会实践活动, 要求学生以小组为单位, 到社会中去调查有关环境污染案例, 分析其 损害的利益, 并提出法律建议。在学习《犯 罪心理学》课程过程中, 组织学生走进监狱, 与犯罪人之间开展面对面的志愿矫正实践 活动, 促使学生在感受知识价值的同时, 激 发他们为社会、为犯罪人驱除黑暗, 带来光 明的伟大使命感。为了使学生深刻认识 “社 区矫正” 的重大意义, 鼓励学生走进基层矫 正机构一一司法所做一名社区矫正志愿者, 通过志愿活动实践刑法学对人关注、对人价 值肯定的人文精神。

此外教师还可以以消费者权益保护日、 法制宣传日等为契机，带领学生走向社会、 走进社区, 开展义务法律咨询宣传活动。通 过实践活动, 使学生内在的人文知识升华为 人文精神。

\section{5. 结束语}

一国法律教育的得失, 关乎国家法治的 前途, 法学专业课程教学承载着培养信仰法 治忠诚与正义法律人才的重大使命。法学的 课堂应是充满了知识教育和精神教育、灵魂 教育的课堂, 法学教师应积极自觉地采取各 种路径使专业课堂成为人文素质教育的有 效阵地, 寓人文精神于课程教学气氛之中, 施人文精神于无形熏陶之中, 实现科学知识 和人文精神的和谐统一。

\section{References}

[1] Max weber, The Protestant ethic and the spirit of capitalism, Anhui people's press, 1997

[2] Ye bifeng, The humanistic spirit of administrative law, Cambridge university press, 2005

[3] Wu xueting, An introduction to criminal justice humanistic spirit, Criminal Science, pp.3-10, 2010

[4] Sun xiaolou, Legal education, China university of political science and law press, 1997 